\title{
Dual sensory impairment in special schools in South-Eastern Nigeria
}

\author{
Ada E Aghaji, ${ }^{1}$ Richard Bowman, ${ }^{2}$ Vincent C Ofoegbu, ${ }^{3}$ Andrew Smith ${ }^{4}$
}

${ }^{1}$ Department of

Ophthalmology, University of Nigeria, Enugu, Nigeria

${ }^{2}$ International Centre for Eye Health, London School of Hygiene \& Tropical Medicine, London, UK

${ }^{3}$ Department of Otorhinolaryngology, University of Nigeria Teaching Hospital, Enugu, Nigeria

${ }^{4}$ International Centre for Evidence in Disability, London School of Hygiene \& Tropical Medicine, London, UK

\section{Correspondence to} Dr Ada E Aghaji, Department of Ophthalmology, University of Nigeria, Enugu Campus, Nigeria; aaghaji@yahoo.co.uk, ada.aghaj@unn.edu.ng

Received 23 May 2016 Revised 4 December 2016 Accepted 10 December 2016

\section{ABSTRACT}

In a cross-sectional study to determine the magnitude of dual sensory impairment (DSI-combined hearing and vision loss) in children in single-disability special education schools, children in schools for the blind and schools for the deaf in four states in South-East Nigeria were examined by an ophthalmologist and otorhinolaryngologist to determine the level of their disability and to identify other disabilities if any.

Participants were all students with childhood blindness or childhood deafness. The magnitude and causes of DSI and the burden of undetected DSI were the main outcome measures. A total of 273 students were examined. About $7 \%$ of these students had DSI out of which over $60 \%$ (12/19) was previously undetected. There was more DSI in the blind schools than in the deaf schools $(p=0.003)$. There is a large burden of undetected DSI in children in special schools in Nigeria. There is a need to create awareness of this problem and advocate appropriate screening, rehabilitative and educational strategies for children who have it.

\section{BACKGROUND}

Children with a disability may often have additional undetected disabilities. This is especially important in low income, middle income countries (LMICs) where inclusive education is not implemented and special schools usually only cater for children with a single disability. Dual sensory impairment (DSI) is the condition of being affected by a combination of varying degrees of visual and hearing loss. It has also been called deafblindness. ${ }^{12}$ Its prevalence ranges from $0.01 \%$ to $1.3 \%$ in the general population but there is a paucity of data on the prevalence of DSI in children. ${ }^{3}$ However, in Denmark the prevalence of deafblindness in children has been estimated to be 1:29000 (0.3/ $10000)^{4}$ and $11 / 110200$ or $1 / 10000$ population in the UK. ${ }^{5}$ A recent survey of childhood sensory and physical impairments in Bangladesh did not report any case of DSI. ${ }^{6}$ Nigeria is an LMIC with a population of about 170 million people. About 30 million are $\leq 5$ years, while 88 million are $<18$ years, (2012). ${ }^{7}$ The prevalence of DSI in Nigerian children is unknown. However, the prevalence of childhood blindness and hearing loss in Nigeria is estimated to be $1.6 / 10000$ children $^{8}$ and $13.9 \%$, respectively. ${ }^{9}$ Several studies in schools for the deaf in both developed and LMIC countries have revealed a high proportion (24-61\%) of deaf students with ocular disorders. These range from non-visually disabling lesions like chalazion and blepharitis to sight-threatening lesions like retinitis pigmentosa. ${ }^{10-12}$ A study in a deaf school in South-West Nigeria also revealed that 1.3\% students were blind and $3.2 \%$ were visually impaired. ${ }^{13}$ Blind children may also have undetected forms of hearing impairment (HI). Deafness is the 'hidden disability' or 'unseen deformity' frequently unnoticed by the general public and health workers. ${ }^{14}$ DSI affects social, cognitive and language development especially if hearing or visual loss is undetected in the critical early years of life. ${ }^{1}{ }^{12}$ The aim of this study is to determine the magnitude and causes of DSI in special schools in South-East Nigeria.

\section{METHODS}

This was a multidisability study and part of the methodology has been reported elsewhere. ${ }^{15}$ All the schools for the blind and deaf in South-Eastern Nigeria were visited.

The eye examination included visual acuity measurement, anterior segment examination with a simple head loupe and pen-torch and dilated funduscopy using a Keeler Spectra indirect ophthalmoscope. The ocular examinations were done by an ophthalmologist (AEA) and the findings were recorded on the WHO Prevention of Blindness form. Refraction, when indicated was performed by the optometrist. A brief history was taken by an experienced otorhinolaryngologist. In the deaf schools, this was interpreted by a teacher using signing. Additional history was obtained by mobile phone from the participants' parents.

Ear examination was done by the otorhinolaryngologist using an illuminated loupe and an otoscope. Those with ear problems, for example, wax, otorrhoea, foreign bodies were treated on site or referred to the nearest Ear, Nose and Throat facility. Audiometry was done in the quietest part of the school using an Oscilla battery-powered screening audiometer model SM 910. The ambient noise was recorded using a Maplin sound meter. Ambient noise did not exceed $40 \mathrm{dBA}$. The hearing thresholds at $0.5 \mathrm{KHz}, 1.2 \mathrm{KHz}$ and $4 \mathrm{KHz}$ were measured for each ear. The average threshold was calculated for each ear while the lower threshold was taken as hearing threshold of the participants according to $\mathrm{WHO}$ guidelines. ${ }^{16}$ All findings were recorded on the WHO/PBH form according to WHO coding instructions. ${ }^{17}$ The data were entered into a specially created database in Microsoft Access and transferred to STATA V.12.1 (Statcorp, Texas, USA) using STATransfer. From here frequency tables were generated. Differences in proportions of children with DSI by school type and age group were analysed using the z-test statistic in STATA. Tests of significance were set at the $95 \%$ level.

\footnotetext{
To cite: Aghaji AE,
Bowman R, Ofoegbu VC, et al. Arch Dis Child 2017;102:174-177.
} 
Table 1 WHO categories of vision of the participants

\begin{tabular}{|c|c|c|c|c|}
\hline $\begin{array}{l}\text { WHO vision } \\
\text { category }\end{array}$ & $\begin{array}{l}\text { Level of } \\
\text { vision }\end{array}$ & $\begin{array}{l}\text { Blind } \\
\text { schools }\end{array}$ & $\begin{array}{l}\begin{array}{l}\text { Deaf } \\
\text { schools }\end{array} \\
\mathrm{n}(\%)\end{array}$ & $\begin{array}{l}\text { Total } \\
\text { n (\%) }\end{array}$ \\
\hline Not impaired & $6 / 6-6 / 18$ & $0(0.0)$ & $139(95.1)$ & $139(50.9)$ \\
\hline Visually impaired & $<6 / 18-6 / 60$ & $3(2.4)$ & $3(2.1)$ & $6(2.2$ \\
\hline SVI & $<6 / 60-3 / 60$ & $11(8.6)$ & $1(0.7)$ & $12(4.4)$ \\
\hline Blind & $<3 / 60-\mathrm{PL}$ & $48(37.8)$ & $0(0.0)$ & $48(17.6)$ \\
\hline Blind & NPL & $65(51.2)$ & $0(0.0)$ & $65(23.8)$ \\
\hline Believed sighted* & & $0(0.0)$ & $3(2.1)$ & $3(1.1)$ \\
\hline Total & & $127(100.0)$ & $146(100.0)$ & $273(100.0)$ \\
\hline
\end{tabular}

${ }^{*}$ All the believed sighted were $\leq 7$ years old.

Approval was obtained from the London School of Hygiene and Tropical Medicine, from the University of Nigeria Teaching Hospital Medical Ethics Review Board and also the State ministries of education. Informed consent to have the children examined was obtained from the parents of the children and head teachers of the participating schools.

\section{Study definitions}

Blindness and visual impairment were classified according to WHO categories. ${ }^{18}$ Similarly, deafness and HI were classified according to WHO hearing-level categories. ${ }^{16}$ The WHO categories of blindness and $\mathrm{HI}$ are shown in tables 1 and 2, respectively. For the purpose of this study, disabling hearing loss was taken as any participant with an audiometric reading of $>40 \mathrm{~dB}$ in the better ear.

Participant: consenting student who developed HI or visual impairment before the age of 15 years.

DSI: For the purpose of this study, DSI was defined as presenting $\mathrm{VA}<6 / 18$ in the better eye and average audiometric reading $>40 \mathrm{~dB}$ in the better ear.

Subjective DSI: DSI detected in a participant by staff or pupils without any objective measurement.

Objective DSI: DSI in a participant detected by audiological and visual testing.

Special school: a school that exclusively educates the deaf or the blind students.

\section{RESULTS}

There were 273 participants. In the blind schools the coverage was $127 / 139(91.4 \%)$ while in the deaf schools it was $146 / 167$
$(87.4 \%)$. The male female ratio was $1.2: 1$. Their mean age was $14.7 \pm 4.6$ years.

The majority (95.1\%) of children in the deaf schools had normal vision, while $89 \%$ of children in the blind schools were blind as shown in table 1.

In the blind schools, almost $30 \%$ of students were considered to have slight $\mathrm{HI}$ while $12 \%$ of them had disabling $\mathrm{HI}>40 \mathrm{~dB}$. The various grades of $\mathrm{HI}$ of the children are shown in table 2.

DSI was detected by the schools in $<3 \%$ cases (subjective) while the rest were diagnosed after the study (objective) as shown in table 3.

\section{Detected (subjective) DSI}

There were seven subjective cases of DSI in the special schools. The four detected cases of DSI in the deaf schools were visually impaired from Goldenhar's syndrome with limbal dermoids, corneal dystrophy and two cases of correctable refractive error. Their causes of deafness were microtia with congenital aural atresia from Goldenhar's syndrome, postinfective otosclerosis and two cases of undetermined hearing loss.

The three cases of detected DSI in the blind school were blind from optic atrophy, anophthalmos and cataract. The causes of HI were undetermined. Their level of HI ranged from moderate to severe.

\section{Total (objective) DSI}

As many as $19 / 273(7 \%)$ children in the special schools had DSI as shown in table 3 . There was almost a threefold increase in the number of participants that were objectively detected when compared with the subjectively detected cases of DSI. About 12\% $(15 / 127)$ of students in the blind school had objectively determined DSI. There was more DSI in the blind schools than in the deaf schools $(p=0.003)$. About $63.2 \%(12 / 19)$ of DSI was previously undetected. The most common causes of visual impairment in children with DSI in the blind schools were cataract/aphakia $(26.7 \%)$ and measles/VAD (20\%) (as shown in table 4), while in the deaf schools it was refractive error (50\%).

As much as $53.4 \%$ of blindness in students with DSI was avoidable (preventable or treatable). The causes of deafness in deaf students were indeterminate $(82.8 \%)$, suspected congenital rubella syndrome $(6.8 \%)$ and suspected genetic causes (otosclerosis) $(5.5 \%)$.

Among the blind students with DSI two students with corneal lesions had chronic suppurative otitis media, while one student with cataract/aphakia had impacted cerumen in both ears, the removal of which did not change the category of her HI. One

Table 2 WHO categories of hearing of the participants

\begin{tabular}{|c|c|c|c|c|c|}
\hline \multirow[b]{2}{*}{ WHO category } & & \multicolumn{4}{|c|}{ Levels of hearing impairment in the special education schools } \\
\hline & & $\begin{array}{l}\text { Level of hearing } \\
\text { impairment }\end{array}$ & $\begin{array}{l}\text { Blind schools } \\
\text { n (\%) }\end{array}$ & $\begin{array}{l}\text { Deaf schools } \\
\text { n (\%) }\end{array}$ & $\begin{array}{l}\text { Total } \\
\text { n (\%) }\end{array}$ \\
\hline 0 & No impairment & $25 \mathrm{~dB}$ and below & $67(52.7)$ & $0(0.0)$ & $67(24.5)$ \\
\hline 1 & Slight & $26-40 \mathrm{~dB}$ & $38(29.9)$ & $0(0.0)$ & $40(14.7)$ \\
\hline 2 & Moderate & $41-60 \mathrm{~dB}$ & $10(7.9)$ & $5(3.4)$ & $13(4.8)$ \\
\hline 3 & Severe & $61-80 \mathrm{~dB}$ & $2(1.6)$ & $3(2.1)$ & $5(1.8)$ \\
\hline 4 & Profound & $>81 \mathrm{~dB}$ & $0(0.0)$ & $118(80.8)$ & $118(43.2)$ \\
\hline * & Believed deaf & & $3(2.4)$ & $20(13.7)$ & $23(8.4)$ \\
\hline \multirow[t]{2}{*}{ * } & Believed hearing & & $7(5.5)$ & $0(0.0)$ & $7(2.6)$ \\
\hline & Total & & $127(100.0)$ & $146(100.0)$ & $273(100.0)$ \\
\hline
\end{tabular}

Precise audiometric readings could not be obtained. 
Table 3 Dual sensory impairment (DSI) in the special schools

\begin{tabular}{|c|c|c|c|c|c|c|}
\hline & \multicolumn{3}{|l|}{ Subjective DSI } & \multicolumn{3}{|l|}{ Objective DSI } \\
\hline & $\begin{array}{l}\text { Blind schools } \\
\text { n (\%) }\end{array}$ & $\begin{array}{l}\text { Deaf schools } \\
\text { n (\%) }\end{array}$ & $\begin{array}{l}\text { Total } \\
\text { n (\%) }\end{array}$ & $\begin{array}{l}\text { Blind schools } \\
\text { n (\%) }\end{array}$ & $\begin{array}{l}\text { Deaf schools } \\
\text { n } \%\end{array}$ & $\begin{array}{l}\text { Total } \\
\text { n (\%) }\end{array}$ \\
\hline DSI & $3(2.4)$ & $4(2.7)$ & $7(2.6)$ & $15(11.8)$ & $4(2.7)$ & $19(7.0)$ \\
\hline No DSI & 124 (97.6) & $142(97.3)$ & $266(97.4)$ & $112(88.2)$ & $142(97.3)$ & $254(93.0)$ \\
\hline Total & $127(100.0)$ & $146(100.0)$ & $273(100.0)$ & $127(100.0)$ & $146(100.0)$ & $273(100.0)$ \\
\hline
\end{tabular}

student with optic atrophy was suspected to have otosclerosis. All the others had undetermined causes of HI.

\section{DISCUSSION}

This study shows that the majority of DSI was unrecognised. Subjectively, the frequency of blind children with HI was underestimated. This difference in the frequency of objective and subjective identification of children with $\mathrm{HI}$ has been noted in a previous study in Bangladesh. ${ }^{6}$ This is partly because deafness is an unseen deformity and is therefore not easily detected. In children with multiple handicaps, $\mathrm{HI}$ is often overlooked, ${ }^{16}$ yet permanent HIs in children especially of the moderate, severe or profound type has a detrimental effect on language development. ${ }^{19}$ The combination of hearing and vision impairment is more disabling than the sum of the impairments, often referred to as $1+1=3 .{ }^{1}$ This has farreaching consequences for the social, educational and emotional development of the child. The proportion of blind students with disabling hearing loss in this study is comparable to the findings in a study in Liverpool where it was reported that $8 \%$ of visually impaired children were found to have severe hearing loss. ${ }^{5}$

The frequency of DSI in this study doesn't take into account the visually impaired children with mild hearing loss. Though not considered to be disabling, research has shown that even mild hearing loss could have a negative impact on learning in children. ${ }^{20}$ There are no data on the impact of mild HI in blind children and this should be studied. The results of the children with mild hearing loss $(25-40 \mathrm{~dB})$ should be interpreted with caution as the ambient sound level was $\leq 40 \mathrm{dBA}$ and this may confound the results of mild hearing loss. Nevertheless, the majority of students in the blind schools was able to distinguish sounds at $\leq 25 \mathrm{~dB}$ under similar conditions and was deemed to

Table 4 Causes of blindness and levels of hearing impairment of children with DSI in the blind schools

\begin{tabular}{|c|c|c|c|c|}
\hline \multirow[b]{2}{*}{ Causes of blindness } & \multicolumn{2}{|l|}{ Level of $\mathrm{HI}$} & \multirow{2}{*}{$\begin{array}{l}\text { Total } \\
\mathrm{N}\end{array}$} & \multirow{2}{*}{$\begin{array}{l}\text { Per } \\
\text { cent }\end{array}$} \\
\hline & Moderate & Severe & & \\
\hline \multicolumn{5}{|l|}{ Treatable blindness } \\
\hline Cataract/aphakia & 3 & 1 & 4 & 26.7 \\
\hline Buphthalmos & 1 & 0 & 1 & 6.7 \\
\hline \multicolumn{5}{|l|}{ Preventable blindness } \\
\hline $\begin{array}{l}\text { Cornea (measles/vitamin A } \\
\text { deficiency) }\end{array}$ & 3 & 0 & 3 & 20.0 \\
\hline \multicolumn{5}{|l|}{ Others } \\
\hline Optic atrophy & 0 & 2 & 2 & 13.3 \\
\hline Anophthalmos/microphthalmos & 0 & 2 & 2 & 13.3 \\
\hline Disorganised/removed/phthisis & 1 & 0 & 1 & 6.7 \\
\hline Cortical blindness & 2 & 0 & 2 & 13.3 \\
\hline Total & 10 & 5 & 15 & 100.0 \\
\hline
\end{tabular}

DSI, dual sensory impairment; HI, hearing impairment. have no hearing loss. These results however, indicate that children with visual impairment should undergo routine audiological assessment to detect any hearing loss and to treat appropriately and that deaf children should undergo routine visual screening. Special needs children with undetected additional disabilities have been reported in the literature. In a study of children in a special needs school in Wales, about a third of them who had never had an eye test, were found to have significant refractive errors on examination. ${ }^{21}$ Also, in another study of severely or profoundly deaf children in Sheffield, a significant proportion of them was found to be visually impaired. ${ }^{22}$ Therefore, the importance of screening children with one disability for other disabilities cannot be overemphasised. In developed countries, children typically developing are routinely screened for hearing and visual impairments. This screening does not occur in many LMICs, hence Olusanya ${ }^{23}$ suggests universal newborn hearing screening programmes (NHSPs) to detect and treat hearing loss, so as to prevent permanently delayed and damaged speech and language development. However, limited resources and systems mitigate against implementation. This has prompted the advocacy for the development of context-specific strategies for $\mathrm{NHSP}^{24}$ in Nigeria. It has been suggested that school entry hearing screening (SEHS) may be important where legislation to undertake mandatory NHSP is non-existent. ${ }^{25}$ Again, the lack of resources and low level awareness of the risk of $\mathrm{HI}$ are challenges to developing and implementing SEHS by health or educational authorities in Nigeria. ${ }^{26}$ As a fail-safe mechanism, high-risk children could be targeted in the absence of universal coverage, for example, children with a history of familial HI, exposure to ototoxic drugs or otitis media. ${ }^{25}$ Our study shows that in Nigeria, blind and visually impaired children should be included in the 'children at risk list' and routinely screened for HIs at the point of diagnosis. Over $50 \%$ of childhood blindness in LMIC countries is avoidable $^{8}$ (preventable like vitamin A deficiency and measles or treatable like cataract) and this was reflected in the proportion of avoidable blindness in students with DSI. In the UK, children routinely undergo an eye examination at birth, at 6-8 weeks and at school entry. In addition, it is advocated that children with hearing disorders undergo targeted ocular examinations. ${ }^{27}$ In LMICs the situation is different. Institutional childhood vision screening is not routinely done. So, Muhit ${ }^{28}$ suggests a community-based detection, referral, treatment and follow-up programme for childhood blindness. Other authors ${ }^{8} 15$ have suggested opportunistic vision screening of children and the health education of caregivers concerning childhood blindness prevention at any routine point of contact with the health system, for example, postnatal checks, immunisation or in maternal and child health clinics. This has been piloted in Tanzania with moderate $^{\text {success. }}{ }^{29}$ Vision screening has the potential to identify, refer and manage avoidable causes of blindness.

Much of DSI is avoidable. In the deaf schools, $50 \%$ of the deaf children with DSI had correctable refractive errors. However, the cause of $\mathrm{HI}$ in these schools was largely 
indeterminate. This is not unusual as the cause of deafness in LMIC countries is not easy to determine, especially where history is sketchy ${ }^{14}$ and there are no clinical records.

The combined problem of vision and hearing loss is a neglected issue, ${ }^{30}$ more so for children in LMIC countries. The majority of the developed countries have special needs and educational services for people with deafblindness. ${ }^{1}$ In LMICs, educational and social services for childhood disability are undeveloped and tend to alienate rather than integrate disabled children into the wider society. ${ }^{31}$ Also, children with disability are inadequately assessed and therefore their choice of educative rehabilitation may be inappropriate. ${ }^{32}$ The deafblind category is not recognised in Nigeria and hence there is no specific provision for educating the child with DSI. The United Nations Convention for the Rights of People with Disabilities encourages member states to ensure that visually and hearing impaired children are appropriately educated with effective individualised support to maximise their academic and social development. ${ }^{33}$ There is a need to create awareness that this group of persons exists and to formulate policies that will facilitate their inclusion in social and educational environments.

\section{Recommendations}

The majority of DSIs was avoidable. There is a need to build the capacity of primary healthcare workers for early detection of lesions causing blindness or deafness. ${ }^{34}$ Children with one impairment be screened for other impairments as early in life as possible, especially children with visual impairment. Robust context-specific operational research should be carried out to determine the most cost-effective and appropriate strategies for screening. Rehabilitative services for school children should be developed. There should be intersectoral cooperation between the rehabilitative, educational and health services.

\section{Limitations of the study}

The audiological exam was done in a classroom in the quietest area in the school. It was not possible to sound proof the classroom. A portable generator was used to power the audiometer and this may have added to the ambient sound level. Notwithstanding, audiometry was carried out when the ambient sound levels were always $\leq 40 \mathrm{dBA}$.

\section{CONCLUSION}

It is hoped that the results of this study will be used as an advocacy tool for planning intervention strategies for children with disabilities in Nigeria.

Acknowledgements The authors thank Professor Clement Nwawolo for the use of his audiometer, Dr Gilbert Enechi the optometrist, and the staff and students of the special schools in South-East Nigeria.

Contributors Made substantial contributions to the conception or design of the work; or the acquisition, analysis, or interpretation of data for the work: $A E A, R B, A S$ and $E O$. Drafted the work or revised it critically for important intellectual content: $A E A, R B, E O$ and AS. Approved the final version to be published: AEA, RB, EO and AS.

Funding British Council for the Prevention of Blindness.

Competing interests None declared.

Ethics approval Medical Ethics Review Boards of the London School of Hygiene and Tropical Medicine and the University of Nigeria Teaching Hospital.

Provenance and peer review Not commissioned; externally peer reviewed.

Data sharing statement The authors are willing to share the original study protocol and anonymised data set used for the analysis on request to fellow researchers.

\section{REFERENCES}

1 Dammeyer J. Deafblindness: a review of the literature. Scand J Public Health 2014;42:554-62.

2 Moller C. Deafblindness: living with sensory deprivation. Lancet 2003;362:\$46-7.

3 Wittich W, Watanabe DH, Gagné JP. Sensory and demographic characteristics of deafblindness rehabilitation clients in Montréal, Canada. Ophthalmic Physiol Opt 2012;32:242-51.

4 Dammeyer J. Prevalence and aetiology of congenitally deafblind people in Denmark. Int J Audiol 2010;49:76-82.

5 Rogers M. Vision impairment in Liverpool: prevalence and morbidity. Arch Dis Child 1996;74:299-303.

6 Murthy GV, Mactaggart I, Mohammad M, et al. Assessing the prevalence of sensory and motor impairments in childhood in Bangladesh using key informants. Arch Dis Child 2014;99:1103-8.

7 UNICEF. At a glance: Nigeria. UNICEF and the United Nations: UNICEF, 2013.

8 Courtright $\mathrm{P}$, Hutchinson AK, Lewallen S. Visual impairment in children in middleand lower-income countries. Arch Dis Child 2011;96:1129-34.

9 Olusanya BO, Okolo AA, ljaduola GT. The hearing profile of Nigerian school children. Int J Pediatr Otorhinolaryngol 2000;55:173-9.

10 Gogate $\mathrm{P}$, Rishikeshi N, Mehata R, et al. Visual impairment in the hearing impaired students. Indian J Ophthalmol 2009;57:451.

11 Hanioğlu-Kargi Ş, Köksal M, Tomaç S, et al. Ophthalmologic abnormalities in children from a Turkish school for the deaf. Turk J Pediatr 2003;45:39-42.

12 Nikolopoulos TP, Lioumi D, Stamataki S, et al. Evidence-based overview of ophthalmic disorders in deaf children: a literature update. Otol Neurotol 2006;27:S1-24.

13 Onakpoya $\mathrm{OH}$, Omotoye OJ. Screening for ophthalmic disorders and visual impairment in a Nigerian school for the deaf. Eur J Ophthalmol 2010;20:596-600.

14 Holborow C, Martinson F, Anger N. A study of deafness in West Africa. Int J Pediat Otorhinolaryngol 1982;4:107-32

15 Aghaji A, Okoye O, Bowman R. Causes and emerging trends of childhood blindness: findings from schools for the blind in Southeast Nigeria. Br J Ophthalmol 2015;99:727-31.

16 World Health Organisation. Prevention of blindness and deafness, 2016.

17 World Health Organization. WHO ear and hearing disorders survey protocol. 1999

18 World Health Organization. International Statistical Classification of Diseases and Related Health Problems. 10th Revision (ICD-10)-WHO Version for 2016 Chapter VII. H54. 2016.

19 Pimperton $H$, Kennedy CR. The impact of early identification of permanent childhood hearing impairment on speech and language outcomes. Arch Dis Child 2012;97:648-53.

20 Khairi Md Daud M, Noor RM, Rahman NA, et al. The effect of mild hearing loss on academic performance in primary school children. Int J Pediatr Otorhinolaryngol 2010;74:67-70.

21 Woodhouse JM, Davies N, McAvinchey A, et al. Ocular and visual status among children in special schools in Wales: the burden of unrecognised visual impairment. Arch Dis Child 2014;99:500-4.

22 Armitage IM, Burke JP, Buffin JT. Visual impairment in severe and profound sensorineural deafness. Arch Dis Child 1995;73:53-6.

23 Olusanya BO, Luxon LM, Wirz SL. Screening for early childhood hearing loss in Nigeria. J Med Screen 2005;12:115-18.

24 Olusanya BO. Neonatal hearing screening and intervention in resource-limited settings: an overview. Arch Dis Child 2012;97:654-9.

25 Mahomed F, De Wet Swanepoel JA. School age hearing screening. In: Fagan J, ed. Open access guide to audiology and hearing aids for otolaryngologists. South Africa: University of Cape Town, 2014.

26 Olusanya BO, Okolo AA, Adeosun AA. Predictors of hearing loss in school entrants in a developing country. J Postgrad Med 2004;50:173.

27 Solebo AL, Rahi J. Epidemiology, aetiology and management of visual impairment in children. Arch Dis Child 2014;99:375-9.

28 Muhit MA. Childhood cataract: Home to hospital. Community Eye Health 2004;17:19.

29 Mafwiri MM, Kisenge R, Gilbert CE. A pilot study to evaluate incorporating eye care for children into reproductive and child health services in Dar-es-Salaam, Tanzania: a historical comparison study. BMC Nurs 2014;13:15.

30 Brabyn JA, Schneck ME, Haegerstrom-Portnoy G, et al. Dual sensory loss: overview of problems, visual assessment, and rehabilitation. Trends Amplif 2007;11:219-26.

31 Olusanya BO. State of the world's children: life beyond survival. Arch Dis Child 2005:90:317-18

32 Maulik PK, Darmstadt GL. Childhood disability in low- and middle-income countries: overview of screening, prevention, services, legislation, and epidemiology. Pediatrics 2007;120(Suppl 1):S1-S55.

33 Convention on the Rights of Persons with Disabilitiesresolution/adopted by the General Assembly. 2006. A/RES/61/106. http://www.un.org/disabilities/convention/ conventionfull.shtml (page accessed 7 Aug 2009).

34 CBM. How to include the perspectives of persons with disabilities in the project cycle management guidelines of the EC. In: Naughton C, ed. Make development inclusive. Lyon, France: CBM, 2008. 


\section{ADC Dual sensory impairment in special schools in South-Eastern Nigeria}

Ada E Aghaji, Richard Bowman, Vincent C Ofoegbu and Andrew Smith

Arch Dis Child 2017 102: 174-177

doi: 10.1136/archdischild-2016-311285

Updated information and services can be found at:

http://adc.bmj.com/content/102/2/174

\section{These include:}

References This article cites 27 articles, 11 of which you can access for free at: http://adc.bmj.com/content/102/2/174\#BIBL

\section{Email alerting} service

Receive free email alerts when new articles cite this article. Sign up in the box at the top right corner of the online article.

Topic Articles on similar topics can be found in the following collections Collections ADC Global child health (48)

\section{Notes}

To request permissions go to:

http://group.bmj.com/group/rights-licensing/permissions

To order reprints go to:

http://journals.bmj.com/cgi/reprintform

To subscribe to BMJ go to:

http://group.bmj.com/subscribe/ 